\title{
Long-Term Nickel Contamination Increases the Occurrence of Antibiotic Resistance Genes in Agricultural Soils
}

\author{
Hang-Wei Hu, ${ }^{\dagger}$, Jun-Tao Wang, ${ }^{\dagger}$ Jing Li, ${ }^{\dagger}$ Xiu-Zhen Shi, ${ }^{\ddagger}$ Yi-Bing Ma, ${ }^{\S}$ Deli Chen, ${ }^{\ddagger}$ \\ and Ji-Zheng $\mathrm{He}^{*, \dagger, \ddagger 0}$
}

\begin{abstract}
${ }^{\dagger}$ State Key Laboratory of Urban and Regional Ecology, Research Centre for Eco-Environmental Sciences, Chinese Academy of Sciences, Beijing 100085, China Faculty of

${ }^{\ddagger}$ Veterinary and Agricultural Sciences, The University of Melbourne, Parkville, Victoria 3010, Australia

${ }^{\S}$ National Soil Fertility and Fertilizer Effects Long-term Monitoring Network, Institute of Agricultural Resources and Regional Planning, Chinese Academy of Agricultural Sciences, Beijing 100081, China
\end{abstract}

Supporting Information

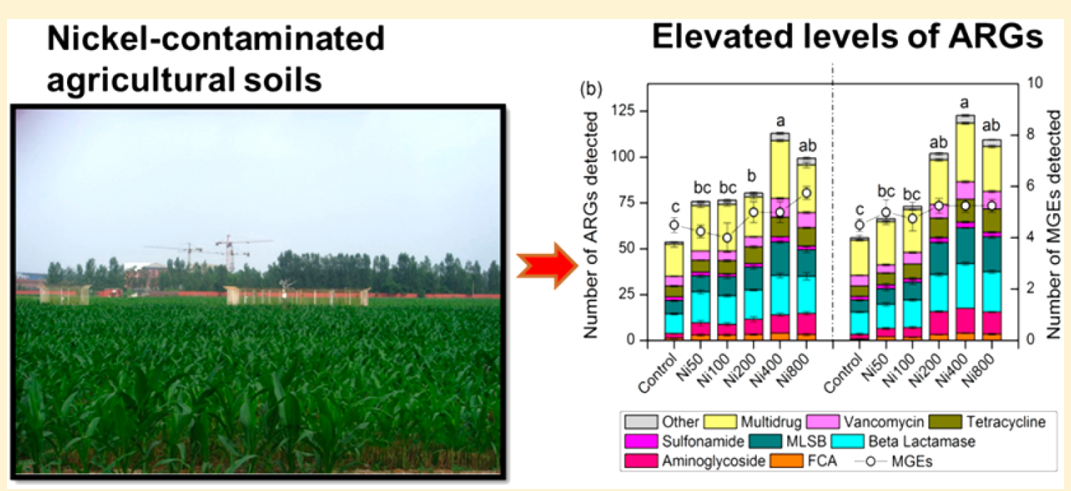

ABSTRACT: Heavy metal contamination is assumed to be a selection pressure on antibiotic resistance, but to our knowledge, evidence of the heavy metal-induced changes of antibiotic resistance is lacking on a long-term basis. Using quantitative PCR array and Illumina sequencing, we investigated the changes of a wide spectrum of soil antibiotic resistance genes (ARGs) following 45 year nickel exposure $\left(0-800 \mathrm{mg} \mathrm{kg}^{-1}\right)$ in two long-term experimental sites. A total of 149 unique ARGs were detected, with multidrug and $\beta$-lactam resistance as the most prevailing ARG types. The frequencies and abundance of ARGs tended to increase along the gradient of increasing nickel concentrations, with the highest values recorded in the treatments amended with $400 \mathrm{mg}$ nickel $\mathrm{kg}^{-1}$ soil. The abundance of mobile genetic elements (MGEs) was significantly associated with ARGs, suggesting that nickel exposure might enhance the potential for horizontal transfer of ARGs. Network analysis demonstrated significant associations between ARGs and MGEs, with the integrase intI1 gene having the most frequent interactions with other cooccurring ARGs. The changes of ARGs were mainly driven by nickel bioavailability and MGEs as revealed by structural equation models. Taken together, long-term nickel exposure significantly increased the diversity, abundance, and horizontal transfer potential of soil ARGs.

\section{INTRODUCTION}

The increasing emergence and propagation of antibiotic resistance genes (ARGs) in clinical and environmental settings is becoming a major threat to human health in the $21 \mathrm{st}$ century. ${ }^{1}$ In the face of almost no new antibiotics in development, antibiotic resistance would threaten the effects of modern medicines, and cause rising difficulties in the treatment of infections. ${ }^{2,3}$ Compelling evidence suggests that the environment is a vast reservoir of antibiotic resistance and that there is evidence for recent exchange of ARGs between environmental bacteria and human pathogens, emphasizing the potential clinical importance of environmental antibiotic resistance. ${ }^{4}$ ARGs are often located on mobile genetic elements (MGEs), and are assumed to be disseminated to other microorganisms and pathogens via the pathway of horizontal gene transfer (HGT), and to be migrated into the food chain after land application of animal manure. ${ }^{5}$ Globally, the proliferation of antibiotic resistance in natural and clinical environments has been mainly attributed to the intensive use of antibiotics in agriculture and medicine. ${ }^{3,6}$ However, apart from the selection pressure imposed by antibiotic use, other components and mechanisms might also contribute to the selection and dissemination of antibiotic resistance. ${ }^{6,7}$ Despite the rising burdens of antibiotic resistance, the potential contribution of environmental ARGs to the clinical reservoirs

Received: July 6, 2016

Revised: December 3, 2016

Accepted: December 15, 2016

Published: December 15, 2016 
of resistance remains largely unknown, ${ }^{8}$ and it is essential to identify the sources and movement of ARGs for design of appropriate strategies to minimize their spread.

Heavy metals, which are common and persist in environmental settings, may be one such factor that indirectly selects for antibiotic resistance. ${ }^{9}$ As alternatives to antibiotics, heavy metals are widely used as feed supplements in the livestock production for growth promotion and disease control, ${ }^{10}$ and are subject to release following land application of fertilizers, pesticides, sewage sludge, and animal manure. ${ }^{11,12}$ Most antibiotics are readily sequestrated and degraded via photolytic and other pathways, and therefore the selection pressure imposed by antibiotic residues rapidly declines over time in the environment. ${ }^{13,14}$ In contrast, heavy metal can accumulate to several orders of magnitude higher than antibiotics and is predicted to persist in agricultural soils with long half-lives. ${ }^{15,16}$ Growing evidence suggested that metal-induced change of antibiotic resistance is an important phenomenon and has a strong selection pressure on bacterial assemblages in various environmental settings. ${ }^{12,15-18}$ Therefore, it is hypothesized that the ubiquitous and rapidly increasing heavy metal contamination in agricultural soils may impose a strong longterm selection pressure for environmental antibiotic resistance. $^{7,11}$

The possibility of heavy metal-induced coselection for antibiotic resistance has been highlighted by several mechanisms, particularly if multiple genes encoding for antibiotic and metal resistance are located on the same MGEs (coresistance) or the same genes confer resistance to multiple types of antibiotics and metals (cross-resistance). ${ }^{9,11}$ Other potential coselection mechanisms used by prokaryotes include indirect but shared regulatory responses to the exposure of antibiotics and metals such as biofilm induction. ${ }^{9}$ To date, only a few studies have investigated the metal-induced selection of antibiotic resistance in environmental settings, including soils amended with copper $(\mathrm{Cu}),{ }^{15,19}$ freshwater microcosms applied with nickel $(\mathrm{Ni})$ and cadmium, ${ }^{17}$ activated sludge bioreactor, ${ }^{20}$ and municipal solid waste leachates. ${ }^{18,21}$ The majority of these studies, however, relied only on culture-dependent approaches and correlative evidence, and focused on a limited number of antibiotics and ARGs. ${ }^{15,22,23}$ Aside from these cases, experimental studies which directly manipulate metal exposure levels to test for metal-driven changes of antibiotic resistance are rare, particularly in the complex soil environment where a direct assessment of metal-induced effect is often hindered by the presence of multiple contaminants. ${ }^{6,24}$ Therefore, it is imperative to understand the role of heavy metal as a selection agent in maintaining environmental antibiotic resistance.

This study was designed to investigate the impacts of longterm $\mathrm{Ni}$ exposure on the diversity, abundance, and horizontal transfer potential of ARGs in two experimental sites with contrasting soil properties. We selected $\mathrm{Ni}$ as the model metal contaminant because it is abundant and widely detected in agro-ecosystems, ${ }^{25-28}$ and is also an essential micronutrient for various cellular functions and components. ${ }^{9}$ The major sources of $\mathrm{Ni}$ in agricultural soils are atmospheric deposition, fertilizers and agrochemical, livestock manures, sewage irrigation and sewage sludge. ${ }^{29}$ A quantitative PCR (qPCR) array containing 296 primer sets was used to survey a wide spectrum of ARGs and MGEs in parallel. ${ }^{24}$ We hypothesized that (i) Long-term Ni exposure can modify the profiles of multiple antibiotic resistance, with increasing $\mathrm{Ni}$ concentrations selecting for enhanced resistance levels; (ii) Changes in ARG patterns are closely associated with MGEs, owing to the genetic linkage of ARGs in MGEs; and (iii) changes in the bacterial community structure, as an important determinant of ARGs, ${ }^{30}$ might be also associated with changes in ARGs in Ni-contaminated soils.

\section{MATERIALS AND METHODS}

Site Description and Soil Sampling. Two long-term experimental stations of the Chinese Academy of Agricultural Sciences, located in Dezhou $\left(37.33^{\circ} \mathrm{N}, 116.63^{\circ} \mathrm{E}\right)$, Shandong, and Qiyang $\left(26.75^{\circ} \mathrm{N}, 111.88^{\circ} \mathrm{E}\right)$, Hunan, China, were selected to provide contrasting soil properties. The soil in Dezhou is classified as a fluvo-aquic soil with a $\mathrm{pH}$ of 7.9 , whereas the soil in Qiyang is classified as a red soil with a $\mathrm{pH}$ of 4.3 . The detailed information about the climatic conditions in the two experimental sites was provided in $\mathrm{Hu}$ et al. (2016). ${ }^{19}$ The field trials were established in July 2007 with six application rates of $\mathrm{Ni}\left(\right.$ as $\left.\mathrm{NiCl}_{2}\right)\left(0,50,100,200,400\right.$, and $800 \mathrm{mg} \mathrm{Ni} \mathrm{kg}^{-1}$ soil $)$ in a randomized block design with four replicate plots $(2 \times 3 \mathrm{~m}$ for each plot) in both sites. The top $20 \mathrm{~cm}$ soils (approximately $1200 \mathrm{~kg}$ for each plot) taken from the field were thoroughly mixed with $\mathrm{NiCl}_{2}$ powder and returned to the plots. The selected $\mathrm{Ni}$ concentrations represented the levels $(<1.0-800$ $\mathrm{mg} \mathrm{Ni} \mathrm{kg}{ }^{-1}$ dry soil) found in a wide range of environmental compartments impacted by agriculture and industry. ${ }^{25-28}$ However, it should be noted that the spikes of 400 and 800 $\mathrm{mg} \mathrm{Ni} \mathrm{kg}{ }^{-1}$ soil in this study are not particularly common and only environmental relevant in some heavily contaminated sites. Wheat in rotation with maize was grown at both sites under conventional agricultural management practices. Inorganic fertilizers (urea, calcium superphosphate, and potassium sulfate) containing no heavy metals were applied to the plots according to local farming practices. The two sites had not been treated with organic manures or biosolids in the previous years. In July 2011 and July 2012, five soil cores $(0-10 \mathrm{~cm})$ taken from each plot were composited into a single sample, and each treatment included four plots. Soil samples were transported to the laboratory on ice, passed through a 2.0 $\mathrm{mm}$ mesh, and archived at $4{ }^{\circ} \mathrm{C}$ before physicochemical analyses and at $-80{ }^{\circ} \mathrm{C}$ prior to molecular analysis.

Soil Physicochemical Analysis and DNA Extraction. Soil physicochemical properties including soil $\mathrm{pH}$, gravimetric water content, soil organic carbon (SOC), total nitrogen (TN), soil microbial biomass carbon (SMBC), extractable Ni concentrations were measured using conventional methods as described previously. ${ }^{19}$ The detailed information about the soil physicochemical properties is shown in Supporting Information (SI) Table S1. The MoBio PowerSoil DNA Isolation Kit (MoBio Laboratories, Carlsbad, CA) was used to extract genomic DNA from $0.25 \mathrm{~g}$ of soil as per the manufacturer's instructions, and the quality of DNA was assessed by NanoDrop ND-2000c UV-vis spectrophotometer (NanoDrop Technologies, Wilmington, DE).

qPCR Analysis of ARGs and MGEs. A qPCR array was performed to determine the diversity and abundance of ARGs using the same primer sets as described previously. ${ }^{24,31}$ The qPCR array contained a total of 296 primer sets, including 285 primer sets which can target all the major classes of antibiotic resistance (including aminoglycosides, $\beta$-lactam, FCA (fluoroquinolone, quinolone, florfenicol, chloramphenicol, and amphenicol), MLSB (macrolide-lincosamide-streptogramin B), sulfonamides, tetracyclines, vancomycin, multidrug, and others), 10 primer sets targeting MGEs (including eight transposase genes and two class 1 integrase genes), and one 
targeting 16S rRNA gene. ${ }^{19}$ The $5 \mu \mathrm{L}$ reaction containing 2.5 $\mu \mathrm{L}$ SensiMix SYBR No-ROX reagent (Bioline, London, UK), 1 $\mu \mathrm{L} 10$-fold diluted DNA, and $0.4 \mu \mathrm{L}$ each primer $(10 \mu \mathrm{M})$ was conducted on a Bio-Rad CFX384 Real-Time PCR Detection System (Bio-Rad, Herculers, CA). ${ }^{19}$ Three technical replicates were included for each soil sample and run in three independent 384-well plates, with each including 296 primer sets, calibrator (as 16S rRNA gene for the same DNA sample for all the plates), and negative control. Amplification conditions were $95{ }^{\circ} \mathrm{C}$ for $10 \mathrm{~min}$, followed by 40 cycles of $95{ }^{\circ} \mathrm{C}$ for $30 \mathrm{~s}$ and $60{ }^{\circ} \mathrm{C}$ for $30 \mathrm{~s}$. The results were screened with the following criteria: (i) a threshold cycle value $\left(\mathrm{C}_{\mathrm{T}}\right)$ of 31 was used as the detection limit; ${ }^{19}$ (ii) samples with more than two replicates above the detection limit were regarded as positive quantification; and (iii) amplicons with multiple melting curves were removed from the analysis. The $2^{-\Delta \mathrm{CT}}$ method where $\Delta C_{\mathrm{T}}=\left(C_{\mathrm{T} \text { detected ARGs }}-C_{\mathrm{T}} 16 \mathrm{~S}\right.$ rRNA gene $)$ was used to calculate the relative abundances of ARGs and MGEs compared to the $16 \mathrm{~S}$ rRNA gene in each soil sample according to a comparative $C_{\mathrm{T}}$ method. ${ }^{32}$

High-Throughput Illumina Sequencing. The hypervariable V4-V5 regions of the bacterial 16S rRNA gene were amplified using the primers $515 F / 806 \mathrm{R}$ which has few taxonomic biases. ${ }^{33}$ The primers were modified by adding adaptor $\mathrm{A}$ to the forward primer, and adaptor $\mathrm{B}$ with 12 nucleotide barcodes to the reverse primer. The details for the PCR reaction mixture, amplification conditions and PCR product purification, and the paired-end sequencing on the Miseq platform have been described in our previous study. ${ }^{19}$ The obtained raw sequences were merged using fast length adjustment of short reads (FLASH), ${ }^{34}$ quality filtered and assigned to individual samples using Quantitative Insights Into Microbial Ecology (QIIME) following the standard operation procedure. $^{35}$ A chimera filtering approach, UPARSE, was used to cluster the quality-filtered reads into operational taxonomic units (OTUs) at a 97\% identity level on the Bio-Linux platform. ${ }^{36}$ A set of representative sequences retrieved from each OTU were aligned by using PyNAST ${ }^{37}$ against the Greengenes reference set. ${ }^{38}$ The Ribosome Database Project Classifier with a confidence threshold of 0.80 was used to conduct the taxonomic classification. ${ }^{39}$ The same number of sequences $(47,011)$ was randomly selected for each sample to compensate for variability in sequencing depth before the downstream analysis. The Illumina sequencing reads of the bacterial 16S rRNA gene have been deposited in the European Nucleotide Archive under the accession number ERP017104.

Co-Occurrence Analysis and Network Generation. Network analysis has been widely used to explore the underlying interaction/association among microbial taxa in complex microbial communities. ${ }^{40}$ A correlation matrix was constructed by calculating the pairwise correlation coefficients among the different taxonomic levels of bacteria (including the phylum, family and genus levels) and ARG subtypes which occurred in $\geq 50 \%$ of all the samples in both sites to minimize the artificial association bias in Cytoscape (version 2.8.3) (1 $^{4}$ plug-in CoNet (version 1.1) ) $^{42}$ as previously described. ${ }^{19}$ Briefly, the pairwise interactions/associations were calculated using two correlation methods (Pearson and Spearman) and two dissimilarity methods (Kullback-Leibler and Bray-Curtis). We reduced the potential compositionality biases and falsepositive correlations by running the ReBoot procedure with 100 permutations, and refined the resultant distribution with 1000 bootstraps. We combined the $P$ values from the four methods using the Brown method, and only included significant correlations with a $P$ value $<0.05$ in the downstream analysis. We performed the Benjamini-Hochberg $(\mathrm{BH})$ multiple test as a correction after the merging of $P$ values. The $\mathrm{BH}$ method adjusts the false discovery rate (FDR), which controls the expected number of false positives among all significant relationships. The chance of falsely rejecting the null hypothesis is 0.05 . We imported the resultant pairwise correlations into Cytoscape plug-in Network Analyzer ${ }^{43}$ for visualization, and explored network topology using the Circular (for the ARGsMGEs networks) and Frucherman Reingold (for the ARGsbacteria networks) algorithms in the Gephi platform. ${ }^{44}$ The final networks only displayed statistically robust correlations with a correlation coefficient $(\rho$-value $)>0.8$ and a significance level $(P$-value $)<0.05 .^{19}$

Statistical Analysis. One-way analysis of variance was performed to test the difference in the diversity and relative abundances of ARGs and MGEs and the relative abundance of bacterial phyla across different treatments in SPSS 20 (IBM, Armonk, NY). The abundance of ARGs, MGEs, and bacterial taxa was log-transformed before statistical analysis to meet the normality assumptions. The relationships between the relative abundances of ARGs and MGEs were analyzed using Spearman's rank correlation test. The log-transformed relative abundances of ARG subtypes were displayed in heat maps using the ggplot2 package ${ }^{45}$ in the R platform. ${ }^{46}$ The impacts of long-term $\mathrm{Ni}$ exposure on the ARG compositions were visualized by the nonmetric multidimensional scaling (NMDS) ordinations based on the Bray-Curtis dissimilarity distances, and statistically evaluated by permutational multivariate analysis of variance (PerMANOVA) using the vegan package $^{47}$ with 999 permutations in R. Statistically significant differences were accepted at $P<0.05$.

Structural equation models (SEMs) were constructed to evaluate the direct or indirect effects of $\mathrm{Ni}$ contamination, soil properties (Table $\mathrm{S} 1$ ), the bacterial abundance and community composition, and MGEs on the ARG patterns. SEM is an $a$ priori approach offering the capacity to visualize the casual relationships between variables by fitting data to the models representing causal hypotheses. ${ }^{48}$ The Mantel test was performed to examine the pairwise correlations among these variables using the Ecodist package in $\mathrm{R},{ }^{49}$ and the matrix of resultant $R$ values was imported into AMOS (SPSS Inc., Chicago, IL) for SEMs construction using the maximumlikelihood estimation method. The data used for the Mantel test included the extractable $\mathrm{Ni}$ concentrations, soil properties (including soil $\mathrm{pH}$, gravimetric water content, SOC, TN, and SMBC), the bacterial $16 \mathrm{~S}$ rRNA gene abundance, the bacterial community composition at the $97 \%$ OTU level, and the relative abundance of MGEs and ARGs. The theoretical model assumptions were as follows (SI Figure S1): (i) Ni exposure might have direct influences on MGEs and the ARG patterns; (ii) $\mathrm{Ni}$ exposure could indirectly influence the patterns of MGEs and ARGs by changing the bacterial abundance and community compositions; and (iii) Basic soil properties might have been changed by the long-term $\mathrm{Ni}$ exposure, with potential consequences on the bacterial communities, MGEs and ARGs. We used high goodness-of-fit index $(>0.90)$, low Akaike information criteria (AIC), nonsignificant chi-square test $(P>0.05)$, and low root-mean-square errors of approximation $($ RMSEA $<0.05)$ to indicate the overall good ness of fit for SEMs. Furthermore, we calculated the standardized total effects of distance from $\mathrm{Ni}$ contamination, 
soil properties, bacterial abundance, bacterial community composition, and MGEs on ARGs. The net effect of one factor upon another is calculated by summing all direct and indirect pathways between the two factors.

\section{RESULTS AND DISCUSSION}

Long-Term $\mathrm{Ni}$ Exposure Selected for Increasing Diversity and Abundance of ARGs. The qPCR array containing 285 primer sets targeting ARGs and 10 sets targeting MGEs was used to evaluate the changes in the diversity and abundance of ARGs after 4-5 year Ni exposure in the two agricultural soils. A total of 126 and 140 unique ARGs were detected in the fluvo-aquic and red soils, respectively (Figure 1). In the fluvo-aquic soil, the numbers of ARGs

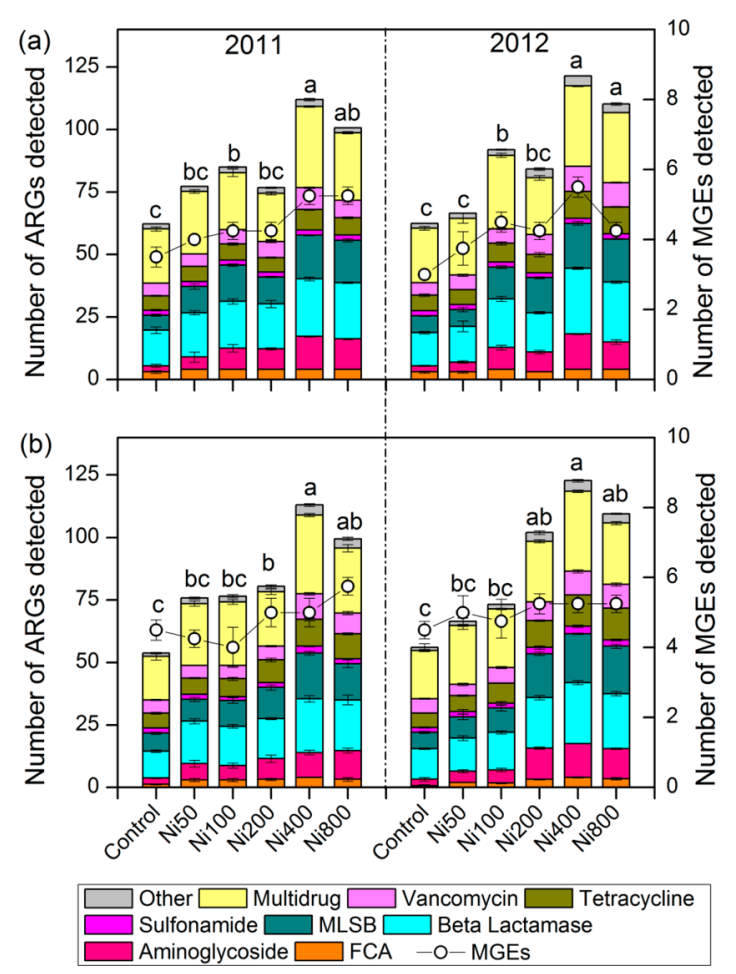

Figure 1. Changes in the numbers of detected ARGs and MGEs along the gradient of $\mathrm{Ni}$ exposure in the fluvo-aquic soil (a) and the red soil (b). Error bars indicate standard errors $(n=4)$. Different letters above the bars indicate a significant difference in ARGs.

significantly increased from 61 to 72 (in the control treatment) to $114-121$ (in the Ni400 treatment) along the gradient of $\mathrm{Ni}$ concentrations $(P<0.05)$, but the highest values were recorded in the Ni400 treatments in both years (Figure 1a). Likewise in the red soil, the numbers of ARGs detected in the control treatments (45-64) showed an increasing tendency toward high $\mathrm{Ni}$ concentrations, with the highest value (116-126) observed in Ni400 as well (Figure 1b). The numbers of ARGs detected in Ni400 were not significantly different from those in Ni800 in both soils $(P>0.05)$. The detected ARG types were mainly dominated by the multidrug and $\beta$-lactam resistance, which comprised $26.2 \%$ and $21.4 \%$ of the total ARGs in the fluvo-aquic soil, and $23.6 \%$ and $20.7 \%$ in the red soil, respectively (Figure 1). Other abundant ARGs could potentially encode resistance to MLSB (15.1\% and $16.4 \%)$, aminoglycoside $(12.7 \%$ and $12.9 \%)$, tetracycline $(8.7 \%$ and $10.0 \%)$, and vancomycin (7.9\% and $7.8 \%)$ in the fluvo-aquic and red soils, respectively. The frequencies of these individual types of ARGs tended to increase along the gradient of increasing $\mathrm{Ni}$ concentrations, and generally exhibited similar patterns as that observed for total ARGs (Figure 1). We further calculated the relative abundances of ARGs (SI Figure S2) by normalizing to the bacterial $16 \mathrm{~S}$ rRNA gene, which mimicked the patterns observed for the diversity of ARGs.

Our findings are in line with previous observations that exposure of bacterial communities to heavy metals coselected for increased bacterial resistance to multiple antibiotics. $7,17,19,50$ The two contrasting agricultural soils exhibited similar ARG patterns in response to $4-5$ year $\mathrm{Ni}$ exposure. The treatments were applied into the field in 2007 with the $\mathrm{Ni}$ concentrations ranging from 0 to $800 \mathrm{mg} \mathrm{kg}^{-1}$ soil, but the extractable $\mathrm{Ni}$ concentrations decreased to $2.2 \pm 0.3-76.3 \pm 1.1 \mathrm{mg} \mathrm{kg}^{-1}$ $(58.9 \pm 1.6$ in Ni400) in the fluvo-aquic soil and $0.8 \pm 0.03-$ $93.7 \pm 1.6 \mathrm{mg} \mathrm{kg}^{-1}(48.7 \pm 3.4$ in $\mathrm{Ni} 400)$ in the red soil (SI Table S1) after 4-5 years of land application. The decrease of $\mathrm{Ni}$ extractability and availability can be mainly attributed to the aging processes, such as adsorption and diffusion $\mathrm{Ni}$ into soil components, and the precipitates of $\mathrm{Ni}$ on the surface of clay minerals and $\mathrm{Al}$ oxides. ${ }^{51}$ It is hypothesized that increasing levels of $\mathrm{Ni}$ exposure would exert increasing selection pressure on antibiotic resistance, and thus the abundance of $\mathrm{Ni}$-induced ARGs would increase along the gradient of $\mathrm{Ni}$ concentrations. At the same time, however, ARGs are carried by soil bacteria, and the bacterial abundance was observed to continuously decrease along the increasing $\mathrm{Ni}$ concentration gradient (SI Figure S3) due to the toxicity effect of $\mathrm{Ni}$ on soil bacteria., 6,11 Therefore, two forces (the increasing selection pressure and the decreasing bacterial abundance with increasing Ni levels) are driving the changes of ARGs toward opposite directions along the Ni gradient, and the maximum level of ARGs would appear if the two forces reached a balance. In this study, the extractable $\mathrm{Ni}$ concentrations around $48.7-58.9 \mathrm{mg} \mathrm{kg}^{-1}$ in Ni400 seemed to be the balance point, where the maximum selection effect on antibiotic resistance was observed, but the Ni800 treatments (with extractable $\mathrm{Ni}$ of $76.3-93.7 \mathrm{mg} \mathrm{kg}^{-1}$ ) are assumed to have excessive $\mathrm{Ni}$ bioavailability resulting in a significant decrease in soil bacterial abundance (SI Figure S3). Therefore, soil bacteria could develop increasing antibiotic resistance before reaching the optimum $\mathrm{Ni}$ concentrations for selection of antibiotic resistance in Ni400, but a decreased level of ARGs was observed in Ni800 of both soils. Our findings caution that if $\mathrm{Ni}$ accumulates to critical concentrations (as the extractable $\mathrm{Ni}$ concentrations found in $\mathrm{Ni400}$ ) in the environment, it can trigger strong indirect selection for antibiotic resistance. However, it is noteworthy that the microbial toxicity of $\mathrm{Ni}$ is highly dependent on the environmental conditions (e.g., soil $\mathrm{pH}$, organic matter contents, the redox potential, vegetation and climatic factors), ${ }^{11,52,53}$ which can affect the valence of the metal ions and therefore the bioavailability and selection pressure of $\mathrm{Ni}$ in soils. Therefore, it is desirable to investigate how environmental ARGs respond to the Ni concentrations by including diverse soil types and various climatic conditions in future studies.

Long-Term Ni Exposure Selected for Increasing Levels of MGEs. The HGT of ARGs among environmental microbial assemblages is an important pathway for the spread of antibiotic resistance in agricultural soils. ${ }^{4,54}$ Most of ARG cassettes are found in co-occurrence with heavy metal resistance genes in MGEs such as integrons, transposons and plasmids, which are frequently detected in agricultural 
systems ${ }^{55}$ and increase in their abundance and diversity under the pressure of environmental pollution. ${ }^{56-58}$ In this study, the qPCR array detected six MGEs (including two integrase genes and four transposase genes) in both soils (Figure 1). The numbers and relative abundances of detected MGEs exhibited an increasing tendency along the gradient of $\mathrm{Ni}$ concentrations (Figure 1 and SI Figure S2), mimicking the patterns of total ARGs in both soils. Spearman's correlation analysis revealed that the relative abundance of total MGEs had significantly positive relationships with those of total ARGs and several major types of ARGs (e.g., aminoglycoside, $\beta$-lactam, multidrug, tetracycline, and vancomycin resistance genes in the fluvo-aquic soil, and aminoglycoside, $\beta$-lactam, MLSB, multidrug, tetracycline, and vancomycin resistance genes in the red soil) (Table 1), suggesting that MGEs might play an important role in the

Table 1. Correlations between the Relative Abundance of ARGs and MGEs in the Fluvo-Aquic Soil and the Red Soil As Revealed by the Spearman'S Rank Correlation Test ${ }^{a}$

\begin{tabular}{llll} 
& \multicolumn{1}{c}{ fluvo-aquic soil } & & \multicolumn{1}{c}{ red soil } \\
\cline { 2 - 3 } total ARGs & \multicolumn{1}{c}{ MGEs } & \multicolumn{1}{c}{ MGEs } \\
FCA & $0.092(0.542)$ & & $0.128(0.526)$ \\
aminoglycoside & $\mathbf{0 . 6 8 7}(<\mathbf{0 . 0 0 1})$ & & $\mathbf{0 . 4 5 0}(<\mathbf{0 . 0 0 1})$ \\
beta lactamase & $\mathbf{0 . 7 2 3}(\mathbf{0 . 0 2 5})$ & & $\mathbf{0 . 7 1 1}(<\mathbf{0 . 0 0 1})$ \\
MLSB & $0.173(0.428)$ & & $\mathbf{0 . 4 8 9}(\mathbf{0 . 0 3 1})$ \\
sulfonamide & $0.153(0.569)$ & & $0.253(0.158)$ \\
tetracycline & $\mathbf{0 . 6 1 5}(\mathbf{0 . 0 3 8})$ & & $\mathbf{0 . 5 2 9}(<\mathbf{0 . 0 0 1})$ \\
vancomycin & $\mathbf{0 . 7 2 6}(<\mathbf{0 . 0 0 1})$ & & $\mathbf{0 . 5 7 1}(<\mathbf{0 . 0 0 1})$ \\
multidrug & $\mathbf{0 . 7 7 6}(<\mathbf{0 . 0 0 1})$ & & $\mathbf{0 . 6 5 8}(<\mathbf{0 . 0 0 1})$ \\
other & $0.152(0.324)$ & & $0.187(0.214)$
\end{tabular}

${ }^{a}$ Values represent the correlation coefficient $R$-values derived from the Spearman's rank correlation test, and values in the brackets represent the $P$-values. Significant correlations $(P<0.05)$ are in bold numbers.

spread of ARGs in $\mathrm{Ni}$ polluted soils, in line with previous findings. ${ }^{19,56,57}$ However, the frequencies of HGT for soil ARGs are influenced by many abiotic factors (e.g., temperature, soil $\mathrm{pH}$, nutrients, and soil types) and biotic factors, ${ }^{59}$ which together with MGEs regulate the actual rates of HGT in the complex soil environment.

Different ARG Patterns in Response to Long-Term Ni Exposure. We further explored the changes in the relative abundances of individual ARG subtypes along the gradient of $\mathrm{Ni}$ exposure using the qPCR array results in heat maps (Figure 2). The resistance profiles of samples (columns in heat maps) were clearly clustered into three categories corresponding to the different $\mathrm{Ni}$ concentrations: low (dominated by samples from the control and Ni50 treatments), medium (dominated by samples from Ni100 and Ni200), and high (dominated by samples from Ni400 and Ni800) Ni exposure levels. This finding was further supported by the gradual shifts of ARGs along the gradient of increasing $\mathrm{Ni}$ concentrations along the first axis of NMDS ordinations based on the Bray-Curtis dissimilarity matrices (Figure 3), which revealed that $\mathrm{Ni}$ exposure had significant effects on the ARG patterns (corroborated by the PerMANOVA test, $P<0.05$ for both soils).

The ARG profiles (rows in heat maps) could be categorized into three patterns (Figure 2): Cluster A had very low abundance or was almost absent at low Ni levels, but markedly increased in their abundances in medium and high Ni levels.
Cluster B represented a minor group of ARGs in $\mathrm{Ni}$ contaminated soils, persisted in a majority of samples with low abundance, and was almost absent in control and low $\mathrm{Ni}$ concentrations. However, this cluster showed apparent enrichment in medium and high $\mathrm{Ni}$ levels in the fluvo-aquic soil, which might be attributed to the selection of less abundant soil indigenous ARGs or evolution of new ARGs under the selection pressure posed by $\mathrm{Ni}$ amendment. ${ }^{9}$ Cluster $\mathrm{C}$, as the most dominant pattern, was prevalent with high abundance across all the samples, suggesting that these ARGs might be carried by soil indigenous microbes which are tolerant of $\mathrm{Ni}$ pressure and might have developed antibiotic resistance before the $\mathrm{Ni}$ amendment. ${ }^{37,60}$ All these three clusters tended to increase in their relative abundances with increasing $\mathrm{Ni}$ concentrations in both soils (PerMANOVA, $P<0.05$ for all the three clusters). The similar patterns of ARGs were also observed in a recent study of the impacts of copper contamination on ARGs in the same experimental stations, ${ }^{19}$ suggesting that similar strategies might be used by soil microorganisms to cope with heavy metal pressure. The clear enrichment of ARGs might be attributed to the increasing selection pressure imposed by the gradient of increasing $\mathrm{Ni}$ concentrations. Alternatively, although $\mathrm{Ni}$ exposure might not necessarily cause increased antibiotic resistance, it might influence the ARG patterns possibly by selecting for $\mathrm{Ni}$ tolerant bacterial species carrying ARGs. Therefore, Ni represents an important metal element which could exert significant influences on the patterns of soil antibiotic resistome and select for increasing resistance levels.

Co-Occurrence Patterns Among ARGs and MGEs. The nonrandom co-occurrence patterns among ARG subtypes and MGEs were explored using the network analysis, and only strong $(\rho>0.8)$ and significant $(P<0.05)$ correlations were displayed. The ARGs-MGEs network included 69 nodes (each node represented a subtype of ARGs or MGEs) and 282 edges, and the entire network was clearly separated into four modules (Figure 4). Compared with random associations, ARGs within the same module may interact more frequently among themselves than with ARGs in other modules, and are supposed to be carried by some specific microbial taxa or MGEs. ${ }^{61}$ Module I was the largest module comprising 29 nodes, followed by Modules II, III and IV including 21, 13, and 6 nodes, respectively. Each module contained a variety of ARG types, and no single module harbored only a single type of ARGs. In each module the most frequently connected node was defined as the "hub". The hubs and the co-occurring ARGs in the same module might be harbored in the same multidrugresistant bacterial taxa or MGEs, ${ }^{19,61,62}$ and thus these hubs were proposed as proxies to predict the occurrence and abundance of the corresponding co-occurring ARGs. ${ }^{61}$ Of particular interest, the "intI1", an important integrase gene, was the hub for Module I comprising 28 co-occurring ARGs, suggesting that the co-occurring ARGs might be harbored in class 1 integrons subject to a synchronous transmission during HGT. $^{56}$

Our findings strongly supported previous studies that suggested using the intIl gene (an integrase gene of class 1 integrons) as a potential proxy for anthropogenic pollution due to its widespread distribution, co-occurrence with other ARGs, and sensitive responses to metal exposure in environmental samples. ${ }^{56-58}$ Therefore, the remarkable diversity of ARGs and MGEs and their significant co-occurrence patterns in the $\mathrm{Ni}$ contaminated agricultural soils may together offer a high 


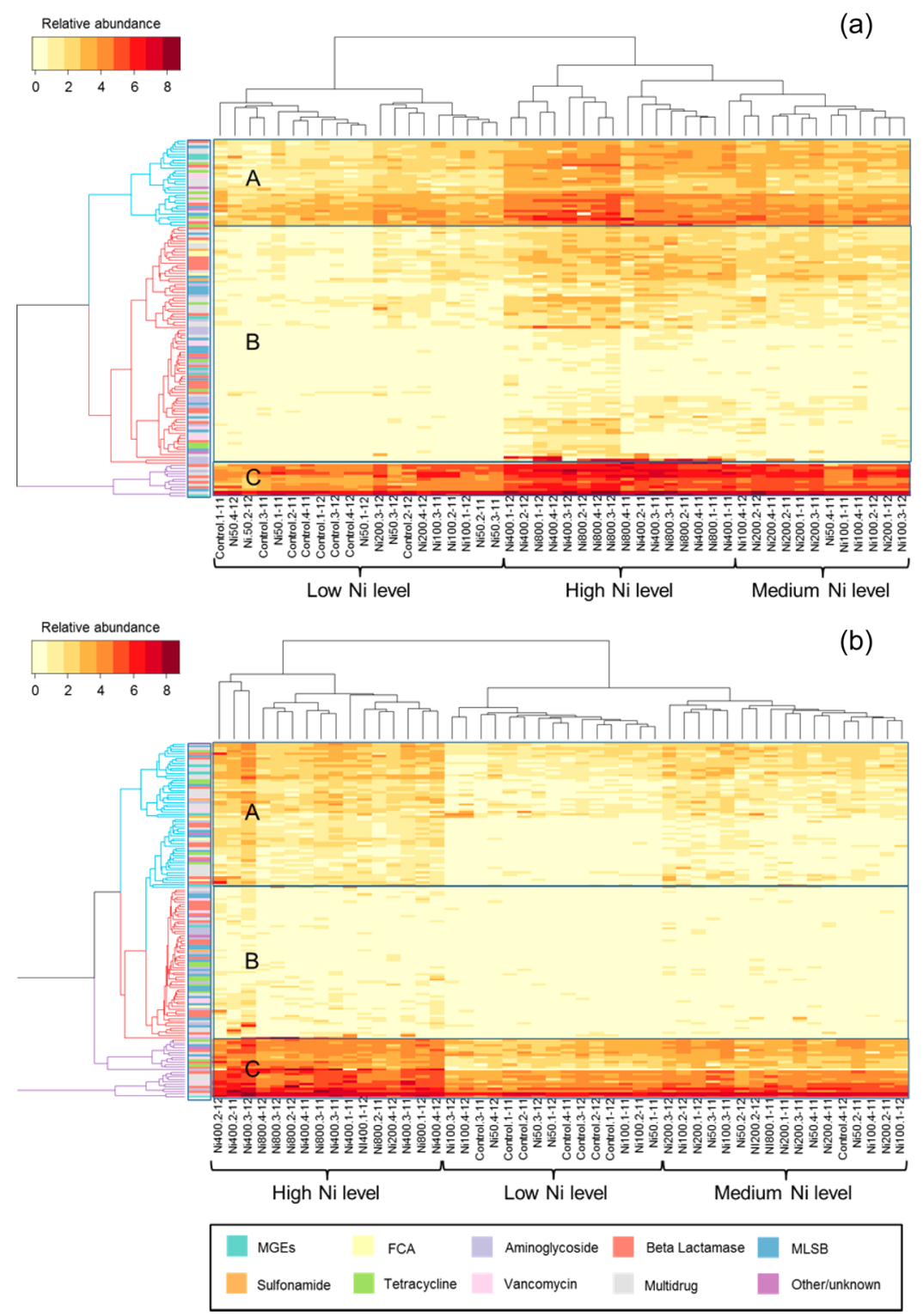

Figure 2. Distribution profiles showing the relative abundances of individual ARG subtypes and MGEs in the fluvo-aquic soil (a) and red soil (b). The labels under each column indicate the treatment names followed by the replication number and the sampling years. For example, Ni400.2-12 represents the second replicate sample collected in 2012 from the Ni400 treatment. Each row displays the relative abundance of a specific ARG subtype. The dendrograms for columns and rows were calculated based on the Bray-Curtis dissimilarities.

likelihood of dispersal, selection, and HGT of ARGs. In addition, the apparent modular structure of ARGs in $\mathrm{Cu}$ contaminated soils ${ }^{19}$ and in our current study hinted that the resistance functions of $\mathrm{Ni}$ and $\mathrm{Cu}$ might be very similar, and amendment of heavy metal could select for an entire suite of ARGs if they are genetically linked, ${ }^{62}$ which necessitates a deep understanding of the colocalization of ARGs and MGEs in resistance islands.

Co-Occurrence Patterns Among ARGs, MGEs, and Bacterial Community. ARG profiles have been reported to vary as a function of the taxonomic composition of bacterial communities, suggesting that the host range of ARGs is a major determinant of ARGs. ${ }^{31,63,64}$ In this study, the soil bacterial community compositions were determined by targeting the bacterial 16S rRNA gene on the Miseq Illumina sequencing platform, which yielded a total of 15421630 high-quality bacterial sequences, with an average of 160642 sequences per sample. The bacterial community in both soils was dominated by Acidobacteria, Actinobacteria, Chloroflexi, Proteobacteria, Firmicutes, Planctomycetes, Gemmatimonadetes, and Verrucomicrobia (SI Figure S4). The relative abundances of these major phyla were significantly altered by the $\mathrm{Ni}$ amendment, and the PerMANOVA test suggested that the total bacterial community composition significantly differed along the gradient of $\mathrm{Ni}$ concentrations $(P<0.05$ for both soils).

To identify the bacterial taxa hypothetically contributing to the prevalence of ARGs, the network analysis was performed to explore the co-occurrence patterns between the ARG types and bacterial taxa (at the levels of phylum, family and genus) (SI Figures S5, S6, and S7). The nonrandom co-occurrence event between ARGs and bacterial taxa might represent an appropriate scenario to track the potential ARG hosts in environmental settings with complex microbial communities. $^{61,64}$ In the network between ARGs and bacterial phyla (SI Figure S5), Cyanobacteria, Actinobacteria, Gemmatimonadetes, Crenarchaeota, and MVP-21 were among the most 

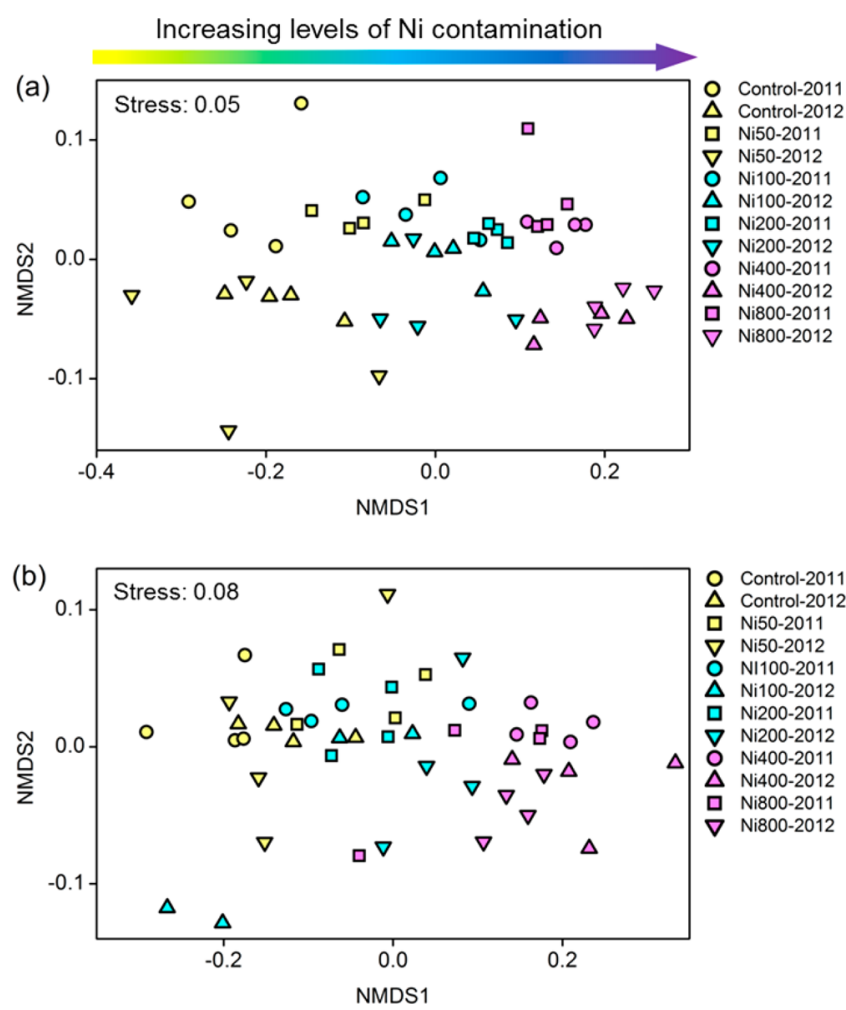

Figure 3. NMDS ordinations derived from the Bray-Curtis dissimilarity matrices showing the changes in the relative abundance of ARGs and MGEs along the gradient of Ni exposure in the fluvoaquic soil (a) and red soil (b). The 2D stress values for both plots are lower than 0.10 indicated that these data are well-represented by the two-dimensional ordinations.

prevalent predicted taxa (as possible ARG hosts), with each phyla containing ARGs encoding resistance to multiple types of antibiotics. For instance, Actinobacteria and Crenarchaeota were had more connections with diverse multidrug resistance genes, and simultaneously they might also harbor genes potentially encoding resistance to $\beta$-lactam. Cyanobacteria were predicted to encompass vancomycin, tetracycline, multidrug, aminoglycoside, and $\beta$-lactam resistance genes. Our results are consistent with previous findings that Actinobacteria and Cyanobacteria are well-known groups of bacteria producing antibiotics, and are frequently detected with multiple drug resistance. $^{31,64,65}$ Meanwhile, multidrug, $\beta$-lactam, MLSB, and aminoglycoside resistance genes showed the strongest relationships with the bacterial communities, and they were predicted to be shared among different bacterial phyla. This finding might explain the observations of widespread $\beta$-lactam resistance in soils, ${ }^{60,64}$ because $\beta$-lactamases are carried by multiple bacterial phyla which can extend the prevalence of $\beta$-lactam resistance to various environmental settings. Therefore, the same ARG types can be distributed in different ARG hosts, and the same bacterial phyla are predicted to carry various types of ARGs, which was further supported by the networks between ARGs and bacterial taxa at the family and genus levels (Figures S6 and S7). These findings indicated that the phylogenetic structure of the bacterial community might be not an important determinant of ARGs in Ni-contaminated soils as those observed in other studies. ${ }^{19,31,60,64}$ This phenomenon might be attributed to the elevated HGT of ARGs mediated by MGEs in Ni-contaminated soils, which can dis-couple ARGs content and bacterial phylogeny and allows for swift acquisition of resistance. $^{66}$

Factors Influencing the Patterns of ARGs in NiContaminated soils. The abundant and diverse ARGs and their increasing tendency along the gradient of $\mathrm{Ni}$ concentrations prompted us to identify the main factors shaping soil ARG patterns. SEM is an a priori approach allowing for an intuitive graphical representation of complex networks of relationships found in ecosystems. ${ }^{48}$ We constructed SEMs to test the casual relationships between $\mathrm{Ni}$ exposure, basic soil properties, the bacterial community abundance and compositions, MGEs, and the ARG patterns in both soils (Figure 5). The results showed that $75 \%$ and $58 \%$ of the total variance of the ARG patterns in the fluvo-aquic and red soils, respectively, could be explained by our SEMs. As for the fluvo-aquic soil (Figure 5a), Ni exposure had significantly positive influences on soil properties $(\lambda=0.61, P<0.001)$, MGEs $(\lambda=0.47, P<$ $0.01)$, and ARGs $(\lambda=0.64, P<0.001)$. Strongly positive effects of MGEs $(\lambda=0.40, P<0.001)$ on ARGs was observed as well. As for the red soil (Figure $5 b$ ), long-term Ni exposure resulted in significant changes in soil properties $(\lambda=0.53, P<0.001)$. Soil properties were observed to have significant effects on the

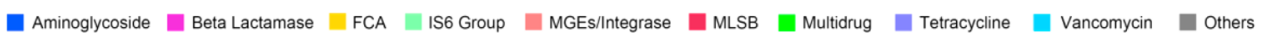

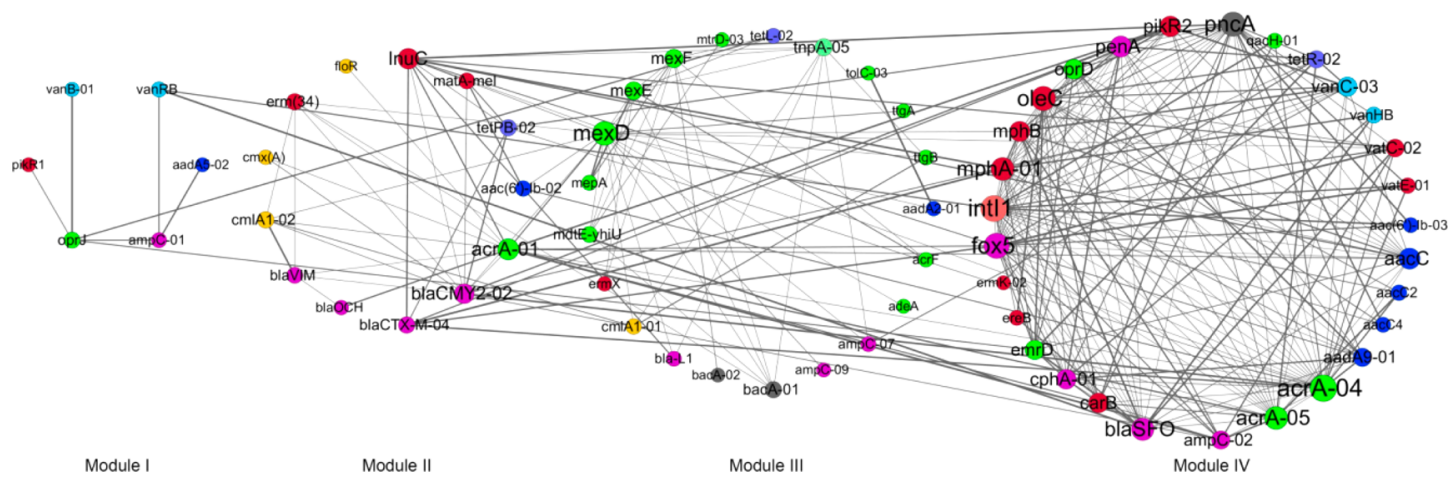

Figure 4. Network showing the co-occurrence patterns among the detected ARG subtypes and MGEs across all the treatments in both soils. The nodes coded with different colors represent different ARGs and MGEs, and the edges correspond to strong and significant correlations between nodes. The size of each node is proportional to the number of significant correlations between nodes. The thickness of the edges is proportional to the correlation coefficient. 

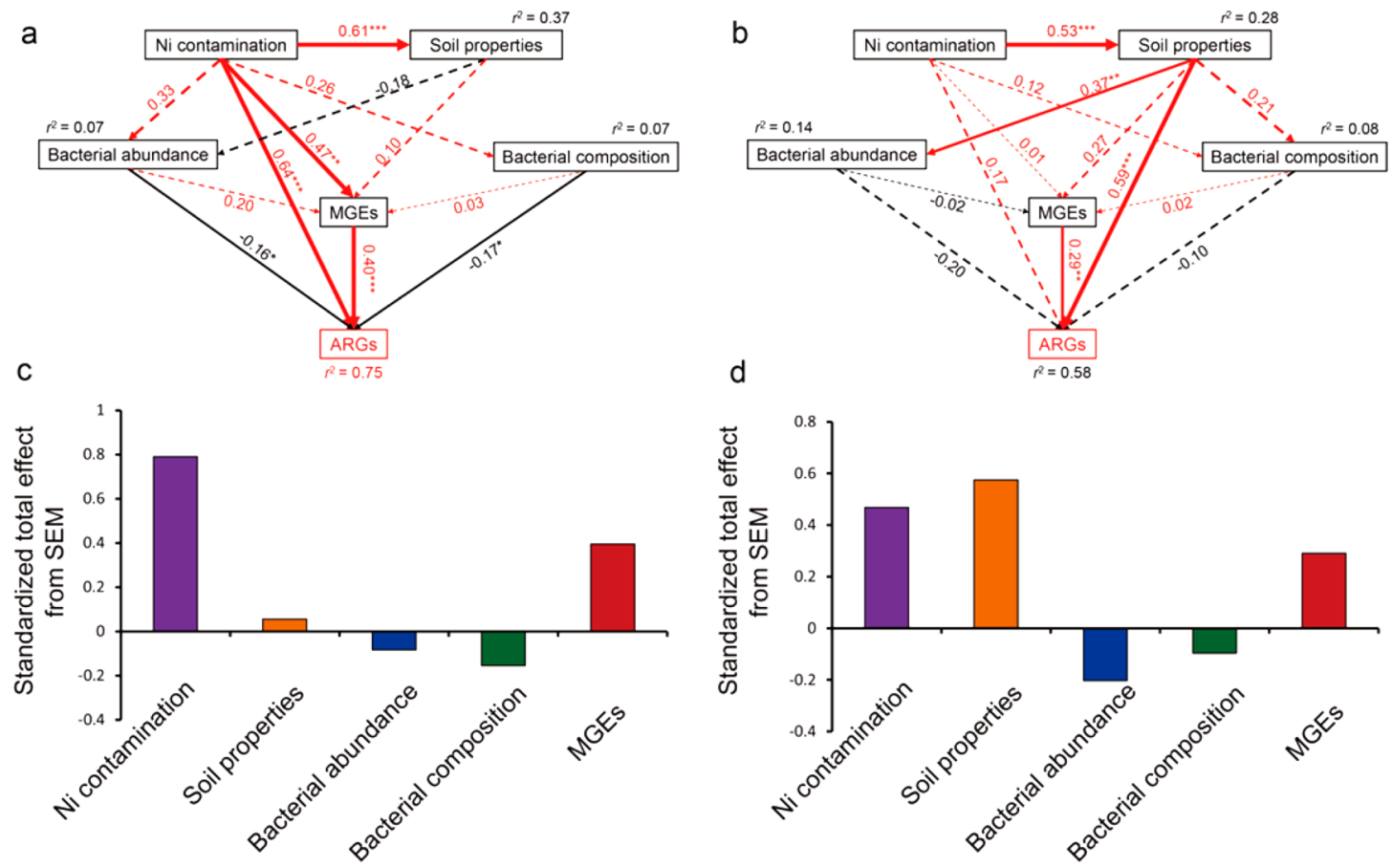

Figure 5. Structural equation models showing the direct and indirect effects of $\mathrm{Ni}$ exposure, soil properties, bacterial abundance, bacterial community composition, and MGEs on the ARG patterns in the fluvo-aquic $(a, c)$ and red soils $(b, d)$. Red and black arrows indicate positive and negative relationships, respectively. Continuous and dashed arrows indicate significant and nonsignificant relationships, respectively. Numbers adjacent to arrows are path coefficients, and width of the arrows is proportional to the strength of path coefficients. $R^{2}$ values denote the proportion of variance explained for each variable. Significance levels are indicated: $* P<0.05, * * P<0.01$, and $* * * P<0.001$. (c,d) Standardized total effects (direct plus indirect effects) derived from the structural equation models. The hypothetical models fit our data well, as suggested by $\chi^{2}=0.6, P=0.91$, GFI $=$ $0.99, \mathrm{AIC}=36.56$, and RMSEA $=0.00$ for the fluvo-aquic soil $(\mathrm{a})$ and $\chi^{2}=0.3, P=0.85$, GFI $=0.99, \mathrm{AIC}=38.33$, and $\mathrm{RMSEA}=0.00$ for the red soil (b).

bacterial abundance $(\lambda=0.37, P<0.01)$ and ARGs $(\lambda=0.59, P$ $<0.001)$. MGEs were also an important factor $(\lambda=0.29, P<$ $0.01)$ in affecting the ARG patterns in the red soil. As indicated by the standardized total effects from SEMs, the patterns of ARGs in both soils were directly influenced by Ni exposure and MGEs, followed by soil properties as an indirect driver, while the contributions of the bacterial community composition to the ARG patterns were trivial and even negligible (Figure 5c and $\mathrm{d}$ ). Taken together, our findings by incorporating all the data into SEMs challenged the previous perceptions of low HGT potential for ARGs in natural settings, ${ }^{64}$ and suggested that the HGT mediated by MGEs, rather than changes in bacterial community composition, were the most dominant factor shaping the ARG profiles in long-term $\mathrm{Ni}$-contaminated sites. Beyond the critical role of MGEs in the adaptation of bacterial communities against heavy metal perturbations, the heavy metal-induced coselection effects might have also contributed to the changes in ARGs which requires in-depth investigations of the expression levels of ARGs and $\mathrm{Ni}$ resistance genes in future studies.

The results of this study supported the findings obtained from another recent study, ${ }^{19}$ in which a wide spectrum of ARGs and MGEs were found to be enriched along a gradient of increasing $\mathrm{Cu}$ concentrations in the same experimental sites. These findings reinforce our understanding of the significant selection pressure on antibiotic resistance imposed by individual types of heavy metals (e.g., $\mathrm{Ni}$ and $\mathrm{Cu}$ ), and future studies are required to elucidate how the different types of heavy metals interact to shape the patterns of environmental ARGs. Despite the significant effects of $\mathrm{Ni}$ and $\mathrm{Cu}$ on ARGs in the two studies, Ni seemed to have stronger selection pressure on antibiotic resistance compared with $\mathrm{Cu}$, as revealed by the more marked increases of ARGs along the Ni gradient (Figure 1 ). The experimental designs of these two studies did not allow a clear decipher of the mechanisms for the different effects of $\mathrm{Ni}$ and $\mathrm{Cu}$. It is supposed that, however, most bacteria in soils might have evolved more tolerance to $\mathrm{Cu}$ than to $\mathrm{Ni}$, because $\mathrm{Cu}$ is generally more abundant than $\mathrm{Ni}$ in various environments, ${ }^{11}$ and the spikes of 400 and $800 \mathrm{mg} \mathrm{Ni} \mathrm{kg}^{-1}$ soil in this study are not particularly common. We also found that the bacterial community composition was the most important determinant of ARGs in the Cu-contaminated soils, ${ }^{19}$ but had very minor roles in the Ni-induced changes in ARGs (Figure 5), which might be attributed to the higher HGT potential for ARGs in Ni-contaminated soils than in $\mathrm{Cu}$-contaminated soils. However, previous studies suggested that both $\mathrm{Cu}$ and $\mathrm{Ni}$ resistance operons can be either chromosomally encoded or plasmid encoded, ${ }^{67,68}$ which cannot explain why there were less bacterial composition-ARGs relationships in the Ni-contaminated soils. Therefore, it is highly desirable to unravel the microbial mechanisms for Ni-induced antibiotic resistance and the link between antibiotic resistance operons and $\mathrm{Ni}$ resistance operons in future studies.

In conclusion, we provide strong field-based evidence that $\mathrm{Ni}$ exposure significantly enhanced the diversity, abundance and HGT potential of a wide spectrum of ARGs in two long-term $\mathrm{Ni}$-contaminated fields. Our results suggest that $\mathrm{Ni}$ contamination could allow for indirect selection of bacteria conferring multiresistance, and thereby contribute to the emergence and dissemination of antibiotic resistance. These findings are 
important for the future evaluation of public health risks associated with the heavy metal-induced selection of antibiotic resistance, and highlight the necessity to take heavy metals into consideration when designing appropriate strategies to reduce the continuous spread of ARGs.

\section{ASSOCIATED CONTENT}

\section{S Supporting Information}

The Supporting Information is available free of charge on the ACS Publications website at DOI: 10.1021/acs.est.6b03383.

Table S1 Basic properties of the fluvo-aquic and red soil samples collected from Dezhou (DZ) and Qiyang (QY), respectively; Figure S1 A priori structural equation model showing the direct and indirect effects of $\mathrm{Ni}$ contamination, soil properties, bacterial abundance, bacterial community composition, MGEs on ARG patterns; Figure $\mathbf{S} 2$ Changes in the relative abundances of ARGs and MGEs normalized to the bacterial $16 \mathrm{~S}$ rRNA gene along the gradient of $\mathrm{Ni}$ exposure in the fluvo-aquic soil (a) and red soil (b); Figure S3 Changes in the bacterial 16S rRNA gene abundance across different $\mathrm{Ni}$-contaminated treatments and the fluvoaquic soil (a) in the red soil (b); Figure S5 The network showing the co-occurrence patterns between ARG types and bacterial taxa at the phylum level across all the treatments; Figure S6 The network showing the cooccurrence patterns between ARG types and bacterial taxa at the family level across all the treatments. Figure S7 The network showing the co-occurrence patterns between ARG types and bacterial taxa at the genus level across all the treatments (PDF)

\section{AUTHOR INFORMATION}

\section{Corresponding Author}

*Phone: (+86) 10 62849788; fax: (+86) 10 62923563; e-mail: jzhe@rcees.ac.cn.

\section{ORCID}

Ji-Zheng He: 0000-0002-3294-102X

Notes

The authors declare no competing financial interest.

\section{ACKNOWLEDGMENTS}

This work was financially supported by the Chinese Academy of Sciences (XDB15020200), and the Australian Research Council (DE150100870, DP170103628).

\section{REFERENCES}

(1) Arias, C. A.; Murray, B. E. Antibiotic-resistant bugs in the 21st century - a clinical super-challenge. N. Engl. J. Med. 2009, 360, 439443.

(2) Berendonk, T. U.; Manaia, C. M.; Merlin, C.; Fatta-Kassinos, D.; Cytryn, E.; Walsh, F.; Bürgmann, H.; Norström, M.; Pons, M. N.; Kreuzinger, N.; Huovinen, P.; Stefani, S.; Schwartz, T.; Kisand, V.; Baquero, F.; Martinez, J. L. Tackling antibiotic resistance: the environmental framework. Nat. Rev. Microbiol. 2015, 13, 310-317.

(3) World Health Organization. Antibiotic Resistance: Global Report on Surveillance; World Health Organization: Geneva, Switzerland, 2014.

(4) Forsberg, K. J.; Reyes, A.; Wang, B.; Selleck, E. M.; Sommer, M. O.; Dantas, G. The shared antibiotic resistome of soil bacteria and human pathogens. Science 2012, 337, 1107-1111.

(5) Marti, R.; Scott, A.; Tien, Y. C.; Murray, R.; Sabourin, L.; Zhang, Y.; Topp, E. Impact of manure fertilization on the abundance of antibiotic-resistant bacteria and frequency of detection of antibiotic resistance genes in soil and on vegetables on harvest. Appl. Environ. Microbiol. 2013, 79, 5701-5709.

(6) Knapp, C. W.; McCluskey, S. M.; Singh, B. K.; Campbell, C. D.; Hudson, G.; Graham, D. W. Antibiotic resistance gene abundances correlate with metal and geochemical conditions in archived Scottish soils. PLoS One 2011, 6, e27300.

(7) Berg, J.; Thorsen, M. K.; Holm, P. E.; Jensen, J.; Nybroe, O.; Brandt, K. K. Cu exposure under field conditions co-selects for antibiotic resistance as determined by a novel cultivation independent bacterial community tolerance assay. Environ. Sci. Technol. 2010, 44, $8724-8728$

(8) Allen, H. K.; Moe, L. A.; Rodbumrer, J.; Gaarder, A.; Handelsman, J. Functional metagenomics reveals diverse betalactamases in a remote Alaskan soil. ISME J. 2009, 3, 243-251.

(9) Baker-Austin, C.; Wright, M. S.; Stepanauskas, R.; McArthur, J. V. Co-selection of antibiotic and metal resistance. Trends Microbiol. 2006, $14,176-182$.

(10) Hvistendahl, M. China takes aim at rampant antibiotic resistance. Science 2012, 336, 795.

(11) Seiler, C.; Berendonk, T. U. Heavy metal driven co-selection of antibiotic resistance in soil and water bodies impacted by agriculture and aquaculture. Front. Microbiol. 2012, 3, 399.

(12) Wright, M. S.; Peltier, G. L.; Stepanauskas, R.; McArthur, J. V. Bacterial tolerance to metals and antibiotics in metal-contaminated and reference stream. FEMS Microbiol. Ecol. 2006, 58, 293-302.

(13) Chee-Sanford, J. C.; Mackie, R. I.; Koike, S.; Krapac, I. G.; Lin, Y. F.; Yannarell, A. C.; Maxwell, S.; Aminov, R. I. Fate and transport of antibiotic residues and antibiotic resistance genes following land application of manure waste. J. Environ. Qual. 2009, 38, 1086-1108.

(14) Kolpin, D. W.; Furlong, E. T.; Meyer, M. T.; Thurman, E. M.; Zaugg, S. D.; Barber, L. B.; Buxton, H. T. Pharmaceuticals, hormones, and other organic wastewater contaminants in US streams, 19992000: a national reconnaissance. Environ. Sci. Technol. 2002, 36, 12021211.

(15) Berg, J.; Tom-Petersen, A.; Nybroe, O. Copper amendment of agricultural soil selects for bacterial antibiotic resistance in the field. Lett. Appl. Microbiol. 2005, 40, 146-151.

(16) Stepanauskas, R.; Glenn, T. C.; Jagoe, C. H.; Tuckfield, R. C.; Lindell, A. H.; McArthur, J. V. Elevated microbial tolerance to metals and antibiotics in metal-contaminated industrial environments. Environ. Sci. Technol. 2005, 39, 3671-3678.

(17) Stepanauskas, R.; Glenn, T. C.; Jagoe, C. H.; Tuckfield, R. C.; Lindell, A. H.; King, C. J.; McArthur, J. V. Coselection for microbial resistance to metals and antibiotics in freshwater microcosms. Environ. Microbiol. 2006, 8, 1510-1514.

(18) Wu, D.; Huang, Z. T.; Yang, K.; Graham, D.; Xie, B. Relationships between antibiotics and antibiotic resistance gene levels in municipal solid waste leachates in Shanghai, China. Environ. Sci. Technol. 2015, 49, 4122-4128.

(19) Hu, H. W.; Wang, J. T.; Li, J.; Shi, X. Z.; Ma, Y. B.; Chen, D.; $\mathrm{He}, \mathrm{J}$. Z. Field-based evidence for copper contamination induced changes of antibiotic resistance in agricultural soils. Environ. Microbiol. 2016, 18, 3896-3909.

(20) Peltier, E.; Vincent, J.; Finn, C.; Graham, D. W. Zine-induced antibiotic resistance in activated sludge bioreactors. Water Res. 2010, 44, 3829-3836.

(21) Graham, D. W.; Olivares-Rieumont, S.; Knapp, C. W.; Lima, L.; Werner, D.; Bowen, E. Antibiotic resistance gene abundances associated with waste discharges to the Almendares River near Havana, Cuba. Environ. Sci. Technol. 2011, 45, 418-424.

(22) Chen, S. C.; Li, X. M.; Sun, G. X.; Zhang, Y. J.; Su, J. Q.; Ye, J. Heavy metal induced antibiotic resistance in Bacterium LSJC7. Int. J. Mol. Sci. 2015, 16, 23390-23404.

(23) McArthur, J. V.; Tuckfield, C. Spatial patterns in antibiotic resistance among stream bacteria: effects of industrial pollution. Appl. Environ. Microbiol. 2000, 66, 3722-3726.

(24) Zhu, Y. G.; Johnson, T. A.; Su, J. Q.; Qiao, M.; Guo, G. X.; Stedtfeld, R. D.; Hashsham, S. A.; Tiedje, J. M. Diverse and abundant 
antibiotic resistance genes in Chinese swine farms. Proc. Natl. Acad. Sci. U. S. A. 2012, 110, 3435-3344.

(25) Mitchell, R. L. Trace elements in soils. In Chemistry of the soil ( $2 d$ ed.); Bear, F. E., Eds.; Reinhold Publishing Corp.: New York, 1964; pp 320-368.

(26) Ure, A. M.; Berrow, M. L. The elemental constituents of soils. In Environmental Chemistry; Bowen, H. J. M., Eds.;2 Royal Soc. Chem.: London. 1982; pp 94-204.

(27) Shacklette, H. T.; Boerngen, J. G. Element Concentrations in Soils and Other Surficial Materials of the Conterminous United States, U.S. Geological Survey Professional Paper 1270; U.S. Gov. Printing Office: Washington D.C., 1984; pp 5.

(28) Holgrem, G. G. S.; Meyer, M. W.; Chaney, R. L.; Daniels, R. B. Cadimium, lead, zinc, and nickel in agricultural soils of the United States of America. J. Environ. Qual. 1993, 22, 335-348.

(29) Luo, L.; Ma, Y. B.; Zhang, S. Z.; Wei, D.; Zhu, Y. G. An inventory of trace element inputs to agricultural soils in China. J. Environ. Manage. 2009, 90, 2524-2530.

(30) Forsberg, K. J.; Patel, S.; Gibson, M. K.; Lauber, C. L.; Knight, R.; Fierer, N.; Dantas, G. Bacterial phylogeny structures soil resistomes across habitats. Nature 2014, 509, 612-615.

(31) Su, J. Q.; Wei, B.; Ou-Yang, W. Y.; Huang, F. Y.; Zhao, Y.; Xu, H. J.; Zhu, Y. G. Antibiotic resistome and its association with bacterial communities during sewage sludge composting. Environ. Sci. Technol. 2015, 49, 7356-7363.

(32) Schmittgen, T. D.; Livak, J. K. Analyzing real-time PCR data by the comparative $C_{T}$ method. Nat. Protoc. 2008, 3, 1101-1108.

(33) Bates, S. T.; Berg-Lyons, D.; Caporaso, J. G.; Walters, W. A.; Knight, R.; Fierer, N. Examining the global distribution of dominant archaeal populations in soil. ISME J. 2011, 5, 908-917.

(34) Magoè, T.; Salzberg, S. L. FLASH: fast length adjustment of short reads to improve genome assemblies. Bioinformatics 2011, 27, 2957-5963.

(35) Caporaso, J. G.; Kuczynski, J.; Stombaugh, J.; Bittinger, K.; Bushman, F. D.; Costello, E. K.; Fierer, N.; Peña, A. G.; Goodrich, J. K.; Gordon, J. I.; Huttley, G. A.; Kelley, S. T.; Knights, D.; Koenig, J. E.; Ley, R. E.; Lozupone, C. A.; McDonald, D.; Muegge, B. D.; Pirrung, M.; Reeder, J.; Sevinsky, J. R.; Turnbaugh, P. J.; Walters, W. A.; Widmann, J.; Yatsunenko, T.; Zaneveld, J.; Knight, R. QIIME allows analysis of high-throughput community sequencing data. Nat. Methods 2010, 7, 335-336.

(36) Edgar, R. C. UPARSE: highly accurate OTU sequences from microbial amplicon reads. Nat. Methods 2013, 10, 996-998.

(37) Caporaso, J. G.; Bittinger, K.; Bushman, F. D.; De Santis, T. Z.; Anderson, G. L.; Knight, R. PyNAST: a flexible tool for aligning sequences to a template alignment. Bioinformatics 2010b, 26, 266267.

(38) McDonald, D.; Price, M. N.; Goodrich, J.; Hawrocki, E. P.; DeSantis, T. Z.; Probst, A.; Andersen, G. L.; Knight, R.; Hugenholtz, P. An improved Greengenes taxonomy with explicit ranks for ecological and evolutionary analyses of bacteria and archaea. ISME J. 2012, 6, 610-618.

(39) Wang, Q.; Garrity, G. M.; Tiedje, J. M.; Cole, J. R. Native Bayesian classifier for rapid assignment of rRNA sequences into the new bacterial taxonomy. Appl. Environ. Microbiol. 2007, 73, 52615267.

(40) Soffer, N.; Zaneveld, J.; Thurber, R. V. Phage-bacteria network analysis and its implication for the understanding of coral disease. Environ. Microbiol. 2015, 17, 1203-1218.

(41) Shannon, P.; Markiel, A.; Ozier, O.; Baliga, N. S.; Wang, J. T.; Ramage, D.; Amin, N.; Schwikowski, B.; Ideker, T. Cytoscape: a software environment for integrated models of biomolecular interaction networks. Genome Res. 2003, 13, 2498-2504.

(42) Faust, K.; Sathirapongsasuti, J. F.; Izard, J.; Segata, N.; Gevers, D.; Raes, J.; Huttenhower, C. Microbial co-occurrence relationships in the human microbiome. PLoS Comput. Biol. 2012, 8, e1002606.

(43) Assenov, Y.; Ramírez, F.; Schelhorn, S.-E.; Lengauer, T.; Albrecht, M. Computing topological parameters of biological networks. Bioinformatics 2008, 24, 282-284.
(44) Bastian, M.; Heymann, S.; Jacomy, M. Gephi: an open source software for exploring and manipulating networks. In International AAAI Conference on Weblogs and Social Media: San Jose, California 2009.

(45) Wickham, H. ggplot2: Elegant graphics for data analysis. Springer-Verlag: New York, 2009.

(46) R Development Core Team. R: A language and environment for statistical computing. R foundation for statistical computing, Vienna, Austria. 2008. http://www.R-project.org.

(47) Dixon, P. VEGAN, a package of R functions for community ecology. J. Veg. Sci. 2003, 14, 927-930.

(48) Eisenhauer, N.; Bowker, M. A.; Grace, J. B.; Powell, J. R. From patterns to causal understanding: structural equation modelling (SEM) in soil ecology. Pedobiologia 2015, 58, 65-72.

(49) Goslee, S. C.; Urban, D. L. The ecodist package for dissimilaritybased analysis of ecological data. J. Stat. Softw. 2007, 22, 1-19.

(50) Gullberg, E.; Albercht, L. M.; Karlsson, C.; Sandegren, L.; Andersson, D. I. Selection of multidrug resistance plasmid by sublethal levels of antibiotics and heavy metals. mBio 2014, 5, e01918-14.

(51) Ma, Y. B.; Lombi, E.; McLaughlin, M. J.; Oliver, I. W.; Nolan, A. L.; Oorts, K.; Smolders, E. Aging of nickel added to soils as predicted by soil $\mathrm{pH}$ and time. Chemosphere 2013, 92, 962-968.

(52) Schulz-Zunkel, C.; Krueger, F. Trace metal dynamics in floodplain soils of the River Elbe: a review. J. Environ. Qual. 2009, 38, 1349-1362.

(53) Nies, D. H. Microbial heavy-metal resistance. Appl. Microbiol. Biotechnol. 1999, 51, 730-750.

(54) Heuer, H.; Schmitt, H.; Smalla, K. Antibiotic resistance gene spread due to manure application on agricultural fields. Curr. Opin. Microbiol. 2011, 14, 236-243.

(55) Gogartion, J. P.; Townsend, J. P. Horizontal gene transfer, genome innovation and evolution. Nat. Rev. Microbiol. 2005, 3, 679687.

(56) Abella, J.; Fahy, A.; Duran, R.; Cagnon, C. Integron diversity in bacterial communities of freshwater sediments at different contamination levels. FEMS Microbiol. Ecol. 2015, 91, fiv120.

(57) Gillings, M. R.; Gaze, W. H.; Pruden, A.; Smalla, K.; Tiedje, J. M.; Zhu, Y. G. Using the class 1 integron-integrase gene as a proxy for anthropogenic pollution. ISME J. 2015, 9, 1269-1279.

(58) Wright, M. S.; Baker-Austin, C.; Lindell, A. H.; Stepanauskas, R.; Stokes, H. W.; McArthur, J. V. Influence of industrial contamination on mobile genetic elements: class 1 integron abundance and gene cassette structure in aquatic bacterial communities. ISME J. 2008, 2, 417-428.

(59) Aminov, R. I. Horizontal gene exchange in environmental microbiota. Front. Microbiol. 2011, 2, 158.

(60) Hu, H. W.; Han, X. M.; Shi, X. Z.; Wang, J. T.; Han, L. L.; Chen, D.; He, J. Z. Temporal changes of antibiotic resistance genes and bacterial communities in two contrasting soils treated with cattle manure. FEMS Microbiol. Ecol. 2016, 92, fiv169.

(61) Li, B.; Yang, Y.; Ma, L. P.; Ju, F.; Guo, F.; Tiedje, J. M.; Zhang, T. Metagenomic and network analysis reveal wide distribution and cooccurrence of environmental antibiotic resistance genes. ISME J. 2015, 9, 2490-2502.

(62) Johnson, T. A.; Stedtfeld, R. D.; Wang, Q.; Cole, J. R.; Hashsham, S. A.; Looft, T.; Zhu, Y. G.; Tiedje, J. M. Clusters of antibiotic resistance genes enriched together stay together in swine agriculture. $m B$ io 2016, 7, e02214-15.

(63) Durso, L. M.; Miller, D. N.; Wienhold, B. J. Distribution and quantification of antibiotic resistant genes and bacteria across agricultural and non-agricultural metageomes. PLoS One 2012, 7, e48325.

(64) Forsberg, K. J.; Patel, S.; Gibson, M. K.; Lauber, C. L.; Knight, R.; Fierer, N.; Dantas, G. Bacterial phylogeny structures soil resistomes across habitats. Nature 2014, 509, 612-615.

(65) D’Costa, V. M.; King, C. E.; Kalan, L.; Morar, M.; Sung, W. W.; Schwarz, C.; Froese, D.; Zazula, G.; Calmels, F.; Debruyne, R.; Golding, G. B.; Poinar, H. N.; Wright, G. D. Antibiotic resistance is ancient. Nature 2011, 477, 457-461. 
(66) Ochman, H.; Lawrence, J. G.; Groisman, E. A. Lateral gene transfer and the nature of bacterial innovation. Nature 2000, 405, 299-304.

(67) Bondarczuk, K.; Piotrowska-Seget, Z. Molecular basis of active copper resistance mechanisms in Gram-negative bacteria. Cell Biol. Toxicol. 2013, 29, 397-405.

(68) Abou-Shanab, R. A. I.; van Berkum, P.; Angle, J. S. Heavy metal resistance and genotypic analysis of metal resistance genes in grampositive and gram-negative bacteria present in Ni-rich serpentine soil and in the rhizosphere of Alyssum murale. Chemosphere 2007, 68, 360367. 